\title{
Editorial
}

\section{Cien días perdidos}

Cuando se hizo notar que las expectativas que el presidente Flores suscitó a lo largo de su campaña electoral no aparecían recogidas en su primer discurso a la nación, se respondió que, aparte de prematuro, era inapropiado que éste incluyera su programa de gobierno. En aquel momento, quienes así opinaron pidieron tiempo, en concreto, los tres meses tradicionales. Cumplido el plazo y ante la insatisfacción de las expectativas, las críticas no se hicieron esperar. Los defensores del gobierno reaccionaron de nuevo, señalando que cien días era muy poco tiempo para ejecutar un plan de gobierno de cinco años y rechazaion la evaluación como una costumbre estadounidense ajena a la realidad salvadoreña -como si este fuera el primer gobierno salvadoreño evaluado después de sus primeros cien días-.

En la discusión subyace algo más importante que la pertinencia de evaluar un gobierno después de sus primeros cien días. Es evidente que no se puede esperar que en un plazo tan breve un gobierno pueda desarrollar todas sus potencialidades y, por lo tanto, no es procedente emitir un juicio definitivo sobre él. Dicho esto hay que agregar que el énfasis en lo obvio busca ocultar la incapacidad del tercer gobierno de ARENA para enfrentar los desafíos de la realidad nacional. Una realidad nacional que, por otro lado, ha sido modelada, en alguna medida, por las acciones y omisiones de sus dos primeros gobiernos. De todas maneras, aquí no interesa discutir si los primeros cien días son apropiados o no para emitir juicios de valor sobre el desempeño del gobierno actual, sino analizar su disposición y su capacidad para responder a la problemática salvadoreńa actual. Si esta hubiera sido la ruta tomada por Flores y su gobierno, la actitud de quienes cuestionan la validez de hacer un alto al cumplirse los primeros cien días sería muy diferente.

\section{Un problema grave de realidad nacional}

Al asumir la Presidencia de la República, Flores renía mucho a su favor para organizar un gobierno orientado al bien común. Por un lado, había 
bastante descontento por el mal gobierno de su antecesor, aun cuando ambos pertenecen al mismo partido, el cambio despertó expectativas; por la política tradicional de ARENA, cuya retórica contrasta cada vez más con la problemática de la realidad nacional y por la extensión de la pobreza y la inseguridad; por el otro lado, contaba con su juventud, su formación, sus buenas maneras, su contacto directo con la población durante el año que duró la campaña electoral, su distanciamiento de la línea de su partido y del gran capital y su compromiso con la búsqueda de soluciones técnicas, en contraposición a la politiquería y a la concesión de privilegios. Se inauguraría así una nueva forma de hacer política, la cual incluso transformaría a ARENA en un partido moderno y lo colocaría a la altura de los tiempos que corren. Sin embargo, la gestión gubernamental de Flores en sus primeros cien días no confirmó estas expectativas.

La característica más notable del nuevo gobierno ha sido su alejamiento de la sociedad y sus problemas, lo cual contrasta con el interés de Flores por escuchar las necesidades de las comunidades y sus organizaciones, sobre todo las menos tomadas en cuenta por los gobiernos anteriores, mientras fue candidato. De ahí que, al cumplir los primeros cien días en el gobierno, las críticas se hayan concentrado en lo que se ha dado en llamar el problema de comunicación del nuevo gobierno, en particular de su presidente. La responsabilidad se atribuye, de manera equívoca, al presidencialismo exagerado que predomina en la práctica política salvadoreña y al intento del gobernante, incomprendido por la población, por superarlo. Al parecer, una de sus prioridades era descentralizar la información, delegando esta importante función en un complejo equipo de comunicación y en los ministros, los presidentes de las autónomas y los superintendentes. Según el plan original, cada uno mantendría informada a la sociedad sobre sus planes, su ejecución y sus avances, reduciendo al mínimo las apariciones del Presidente de la República, quien así podría dedicar más tiempo a pensar sobre los problemas del país y sus soluciones. Pero el nuevo esquema no resistió los primeros tres meses y se derrumbó.

El presidente Flores atribuye este fracaso al presidencialismo exagerado: la gente querría ver y escuchar al Presidente de la República y a nadie más. En consecuencia, haciéndose eco de las críticas, Flores ha decidido aumentar sus apariciones en público. Parte de este plan es el programa dominical que desde hace unas pocas semanas se transmite por radio y televisión y a través del cual el presidente se dirige a la nación - al estilo de los presidentes estadounidenses-; la promesa ya hecha al comienzo de su gestión, pero no cumplida, de hacer una visita semanal al interior del país - comenzando por algunas de las comunidades inundadas por las lluvias-; y la campaña propagandística orientada a promover su imagen y su palabra. A esto se agrega el informe del primer trimestre, que algunos altos funcionarios, siguiendo las instrucciones del mandatario, rindieron ante los medios de comunicación social. Sin em- 
bargo, ninguno de estos esfuerzos ha sido suficiente para aplacar las críticas. La popularidad del gobierno de Flores no parece aumentar.

Las dificultades que el nuevo gobierno ha encontrado en estos primeros cien días se han planteado, de manera incorrecta, en términos de comunicación. Una cosa es la presencia del Presidente de la República $\longrightarrow$ para el caso de los altos funcionarios de su gobierno- en la prensa y en los medios de comunicación y otra mucho más importante - aunque intrínsecamente vinculada a la anterior - es el mensaje que transmiten. El gobierno no ha tropezado tanto con los medios o con la prensa en cuanto tales, sino con la articulación de su propio mensaje. No se trata tanto de cuántas veces el mandatario o los altos funcionarios aparecen en los medios o la prensa, sino de aquello que comunican a la nación. Las generalidades y los tópicos que caracterizan el discurso gubernamental lo hacen vago e irrelevante $y$ no pocas veces ficticio e incomprensible para el ciudadano promedio. En sus intervenciones, ni Flores ni sus colaboradores han conseguido articular su discurso con la problemática nacional, debido a que la evaden cuidadosamente. Sin referirse a ella de una forma explícita, presentan como logros lo que son simples ideas o proyectos. El temor a la realidad ha llevado a que tanto el mandatario como el Ministro de Economía, con la colaboración de la prensa, ensayen las conferencias, filtrando a un mismo tiempo las preguntas y las respuestas. Aquellos periodistas que no se acomodan a esta curiosa modalidad no pueden preguntar.

Si el discurso gubernamental se ocupara de la realidad y fuera veraz, captaría el interés de la sociedad y los funcionarios no tendrían que aparecer muchas veces en los medios. El discurso de Flores adolece de credibilidad y, por lo tanto, de relevancia. La cuestión se ha planteado en términos de comunicación porque lo que más llama la atención es la falta de sintonía del gobierno con el sentir del país. La gran ausente es la realidad nacional. Vistas así las cosas, de poco servirá aumentar el número de apariciones y gastar cientos de miles de colones en propaganda. Un Presidente de la República no puede evadir de forma sistemática la reálidad nacional ni el compromiso con su transformación, al mismo tiempo que asegura estar gobernando para garantizar el bienestar de cada salvadoreño y su familia. El Presidente de la República debe hablar tanto de la coyuntura nacional, regional e internacional como de sus planes a mediano y largo plazo. Debe mostrarse informado y sensible ante el impacto del acontecer en la población. Pero ello exige prestar atención al desarrollo de los acontecimientos y poseer una sensibilidad básica ante las necesidades y aspiraciones de las mayorías populares. De ahí que sea crucial escuchar a la población y a sus organizaciones y no sólo atender a las demandas de las gremiales de la gran empresa privada o de los bancos más grandes.

No se puede desconocer que el presidencialismo predominante exige la presencia continua del Presidente de la República en el acontecer nacional, 
ni que un régimen semejante debiera ser transformado, en cuanto atribuye a aquél mucho más poder que el que constitucionalmente posee, anulando simultáneamente la independencia de los otros poderes estatales; pero tampoco conviene pasar por alto que una dirección visible y firme es imprescindible para conducir a buen término una transición que como la salvadoreña se encuentra a medias y sin rumbo seguro. En estas circunstancias, el retiro del Presidente de la República a un segundo plano puede traer más males que bienes para la estabilidad social y política. Aparte que, en sí mismo, el presidencialismo no es menos democrático que el parlamentarismo. Todo depende de cómo y para quién se ejerza el poder.

La característica más notable del nuevo gobierno ha sido

su alejamiento de la sociedad y sus problemas, lo cual contrasta con el interés de Flores por escuchar las necesidades

de las comunidades y sus organizaciones, sobre todo las menos

tomadas en cuenta por los gobiernos anteriores, mientras fue candidato.

Hasta ahora, Flores ha ejercido el poder desde la distancia y desde la altura. Se ha colocado lejos de la realidad nacional, lo cual a veces es conveniente para poder captar la perspectiva de su acontecer, pero para volver a ella e influir en la dirección de su curso. Flores, en cambio, permanece en la altura y trata el acontecer nacional desde la elevada cumbre del poder presidencial, con lo cual, desautoriza su propio discurso y refuerza el presidencialismo. Desde esta ubicación resulta fácil acomodar los hechos a las ideas con lo cual la realidad se escapa y el discurso, en consecuencia, se queda sin contenido. Flores ha revestido el ejercicio de su magistratura de una dignidad que lo aleja y lo eleva, en lugar de acercarlo y abajarlo. Ambas imprescindibles si lo que se busca es servir a cada uno y a cada una de los salvadoreños, tal como gusta recordar al presidente al finalizar sus intervenciones. No obstante su rechazo del presidencialismo, la dirección que Flores le ha dado a su gobierno es evidente y no hay indicios de que vaya a cambiar de rumbo, aun cuando así lo demande la sociedad y la realidad nacional misma.

No es, pues, la opinión pública la que no comprende al presidente Flores y sus planes de gobierno, sino que es éste quien aparenta no comprender la realidad salvadoreña. Porque bien pudiera suceder que el presidente Flores estuviera intentando ganar tiempo, mientras acostumbra el país a su discurso. Su mayor obstáculo es la realidad misma, cuyas exigencias cuestionan a cada paso los intentos por ideologizarla. 


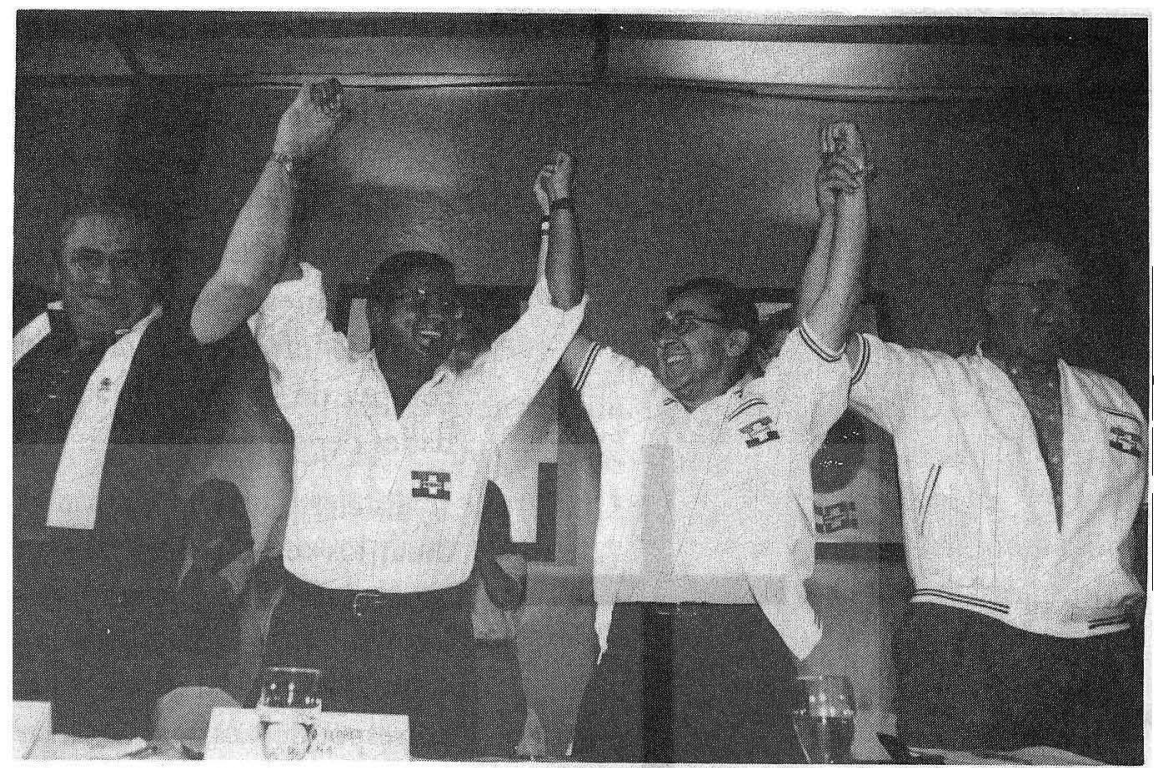

2. Atrapado en las contradicciones de la realidad nacional

La primera desilusión que Flores causó de cara a las expectativas creadas por él mismo y sus allegados fue la designación de su gabinete. La combinación de ministros, presidentes de autónomas, superintendentes y otros altos funcionarios provenientes de los círculos duros y extremistas de ARENA e incluso del gobierno anterior con jóvenes inexpertos no era la más idónea para proyectar la imagen de novedad que, sin duda, Flores pretendía.

Una serie de hechos, algunos de ellos herededados de los dos gobiernos anteriores de Cristiani y Calderón y otros ocurridos durante los primeros cien días de Flores, habla por sí misma del tiempo y los recursos perdidos, los cuales podrían haberse dedicado a responder a los desafios planteados por la realidad nacional, regional e internacional. Sin pretender agotar la lista, entre los hechos más relevantes se encuentran el desabastecimiento de gas propano; la dirección inadecuada de los centros de readaptación de menores y de todo el sistema penitenciario, cuyos internos han protagonizado luchas sangrientas con cierta periodicidad; una ley de armas que en lugar de restringir y controlar, fomenta la libre circulación y uso de casi cualquier tipo de armamento; la ausencia de resultados de un plan de seguridad, publicitado como solución ideal para contener la delincuencia, ejecutado con medios comprobadamente inadecuados; la ineficacia de una policía, cuya dirección está en manos de un especialista en guerra psicológica e inteligencia política; el anuncio de medidas económicas parciales e insuficientes, y el descubrimiento de actos de corrupción de toda clase - un préstamo millonario con un interés irrisorio, destinado a garantizar la liquidez de los dos bancos salvadoreños más grandes, la firma de un contrato oneroso para la nación 


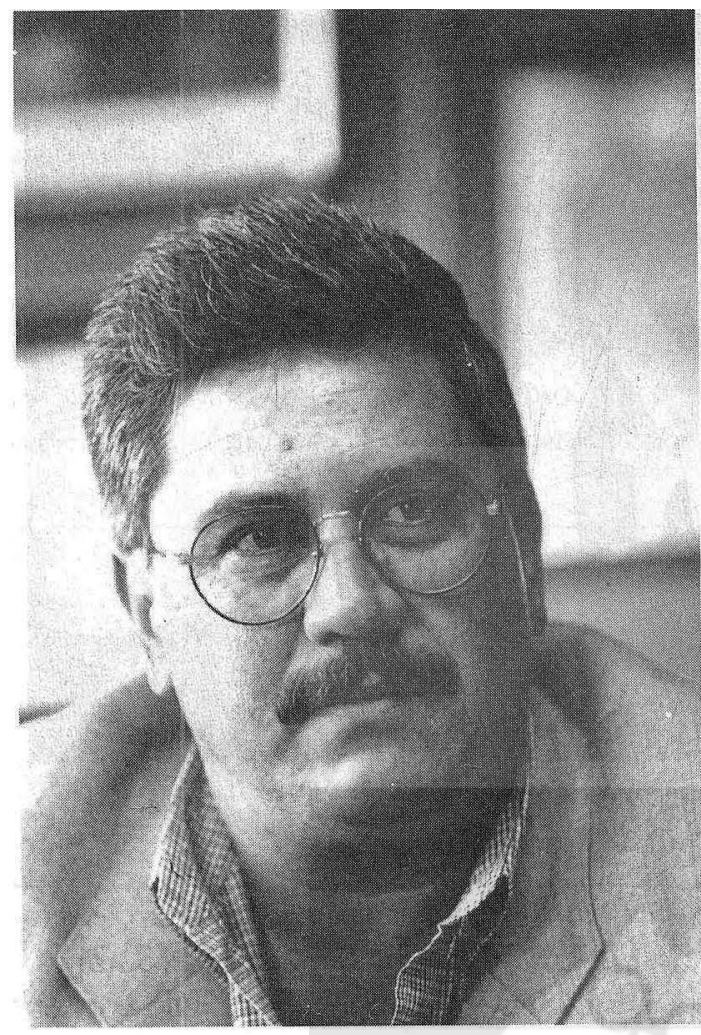

con una empresa productora de energía eléctrica, la tolerancia ante los abusos y las arbitrariedades de las empresas que prestan servicios públicos, la malversación de centenares de millones de dólares en obras de infraestructura, en la compra de votos y en actividades deportivas-.

Es cierto que, en gran medida, los responsables de esta acumulación de hechos son los gobiernos de Cristiani y Calderón, pero al de Flores le corresponde acarrear con las consecuencias, cuanto más porque ambos militan en el mismo partido. Sin embargo, los altos funcionarios del gobierno de Flores no han estado a la altura de los desafíos heredados y nuevos, ya sea por inexperiencia, por incapacidad o simplemente por falta de libertad.

El informe semestral sobre la coyuntura económica del país, elaborado por el Departamento de Economía de la UCA -y publicado en esta misma edición-, vuelve a insistir en que la dirección actual de la política económica hace prácticamente imposible superar la pobreza y el desempleo.

En lugar de dirigir El Salvador hacia un ejercicio del poder más democrático, teniendo como objetivo último la búsqueda del bien común y del bienestar de sus mayorías, el gobierno de Flores, después de tres meses, se encuentra confrontado con sectores importantes del movimiento social organizado. La fecha transcurrió entre las amenazas de las protestas de calle de los ex patrulleros de la Fuerza Armada y las huelgas de los sindicatos del sector público. Las exigencias de indemnizaciones de unos y de subidas salariales de los otros y la negativa gubernamental llevaron a las partes al borde de la confrontación abierta. Aunque la tensión ha cedido, gracias a cierta apertura a negociar por parte de los protagonistas, eso no significa que la 
posibilidad del conflicto haya sido superada. El gobierno de Flores tiene poco espacio para maniobrar ante las exigencias monetarias de los ex patrulleros y los sindicatos, debido a que la tendencia al alza del déficit fiscal está alcanzando niveles inaceptables. Es paradójico que en lugar de avanzar en la implementación del programa social, la parte más interesante de las promesas electorales de Flores y la más urgente para aliviar el deterioro de las condiciones de vida de la mayoría de la población, ahora deba concentrarse en la contención del malestar social.

Las pretenciones que el gobierno de Flores haya podido abrigar para aumentar sustancialmente la inversión social, se han encontrado con unas limitaciones estructurales que, a primera vista, parecen insuperables. En gran medida, estas últimas explican también el creciente malestar en los sectores populares organizados y no organizados. Aun cuando las protestas sean interpretadas en el contexto electoral inmediato, no puede desconocerse la precariedad de las condiciones de la vida de la mayoría de la población salvadoreña. No es arbitrario que la mayor parte de ésta apruebe las exigencias presentadas al gobierno, aunque no los medios utilizados.

El informe semestral sobre la coyuntura económica del país, elaborado por el Departamento de Economía de la UCA - y publicado en esta misma edición-, vuelve a insistir en que la dirección actual de la política económica hace prácticamente imposible superar la pobreza y el desempleo. Uno de los obstáculos principales es la debilidad del crecimiento económico, un requisito indispensable, aunque no suficiente. La tendencia de los últimos tres años significa que para duplicar el crecimiento promedio del producto interno bruto serían necesarios más de siete décadas. Este dato es más dramático si se considera el consumo privado por persona, puesto que duplicarlo tomaría unos siete siglos. Por artificiosos que pudieran parecer, estos cálculos señalan un hecho insoslayable para quienes deciden sobre la política económica salvadoreña y es que con la tasa de crecimiento actual, El Salvador muy difícilmente podrá salir de la pobreza y del subdesarrollo. Mientras tanto, el gobierno continúa proyectando recuperaciones de la tasa de crecimiento más fundamentadas en expectativas que en cálculos sólidos.

Si se observa el comportamiento de los salarios, otro indicador vinculado intrínsecamente al malestar de la población, el panorama es desolador. Según el informe citado antes, los salarios reales (el mínimo y el promedio) han permanecido estancados durante la última década. Peor aún, los índices de los salarios reales se encuentran por debajo del nivel alcanzado en 1989, lo cual contrasta escandalosamente con el crecimiento del producto interno bruto por persona, el cual, entre 1989 y 1999 , creció en un 28 por ciento aproximadamente. Así, mientras los salarios se han mantenido inalterados, los empleadores han aumentado sus ganancias. Más aún, éstas han aumentado a costa de aquéllos. Dicho de otra manera, los beneficios del crecimiento 
no han llegado a los trabajadores, ya no digamos a quienes ni siquiera tienen empleo. Contrario a lo propuesto por los gobiernos de ARENA, el crecimiento de la década de los noventa ha sido marginador y excluyente, en particular en el sector rural.

Esto, naturalmente, repercute en el empleo. La tasa de desempleo ha seguido creciendo, de forma lenta, pero importante. Dada la debilidad del crecimiento económico, no puede ser de otra manera. Aun utilizando los datos del seguro social, porque no existe información suficiente para un estudio más confiable del fenómeno, se observa que el número de trabajadores cotizantes se ha mantenido estable en el último año y medio. Pero el indicador más llamativo es el del subempleo, cuyo crecimiento moderado es señal segura del deterioro sistemático del empleo formal. En esta área, el sector más afectado es el femenino. Esto significa que los sectores productivos, aun cuando han experimentado un crecimiento pequeño en el último año, siguen expulsando mano de obra sistemáticamente, incrementando así el subempleo nacional. Para miles de familias, esto se traduce en menos ingresos, menos poder adquisitivo y menos capacidad para adquirir la canasta básica.

En lugar de dirigir El Salvador hacia un ejercicio del poder más democrático, teniendo como objetivo último la búsqueda del bien común y del bienestar de sus mayorías, el gobierno de Flores, después de tres meses, se encuentra confrontado con sectores importantes del movimiento social organizado.

El malestar causado por el estado de la economía no se reduce a los sectores populares, sino que se ha extendido de manera sorprendente a los sectores medios e incluso altos. La inquietud del sector que no pertenece a la gran empresa es creciente, tanto que, políticamente, está ocasionando fracturas importantes en la alianza en la que ARENA asienta sus pilares. La explicación de este descontento también se encuentra en el informe semestral del Departamento de Economía de la UCA. Ahí se constata que mientras el sector financiero crece de una forma bastante dinámica, el comercial lo hace de una manera lenta, mientras que el industrial experimenta una reducción y el agropecuario se sumerge en la crisis. A ello se agregan unas tasas de interés extremedamente altas, lo cual pone en entredicho que los índices macroeconómicos tengan la solidez que el gobierno pregona. No es posible que un país con una estabilidad macroeconómica como la que el gobierno atribuye a El Salvador, tenga al mismo tiempo unas tasas de interés tan elevadas. Si el mercado establece estas tasas es porque sus expectativas sobre la economía salvadoreña no son positivas y porque le atribuye, en consecuencia, un factor 


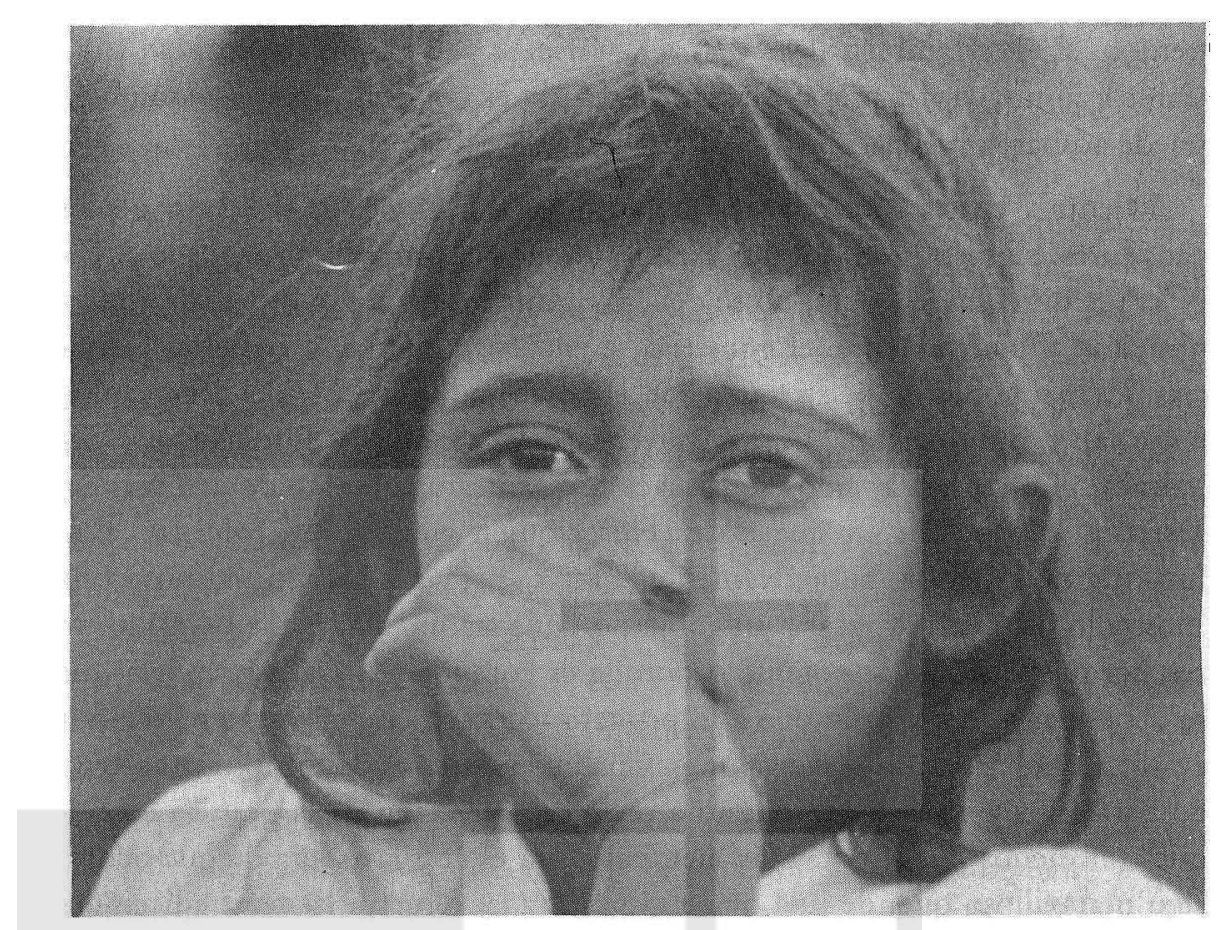

de riesgo elevado. Estos riesgos vendrían dados por la inseguridad, la impunidad y la obsolescencia de la ley.

Para las empresas, la tasa de interés elevada supone un costo también elevado del servicio de su deuda, lo cual ha puesto en peligro sus balances financieros. Muchas empresas han caído en mora y son cada vez más las que se ven obligadas a cerrar o a vender a empresas más grandes - con frecuencia a multinacionales-. El incremento de la mora bancaria, la cual se ha duplicado en ańo y medio, no sólo amenaza la actividad productiva, sino también a los bancos mismos. De hecho, el gobierno de Flores se ha visto obligado a salir en defensa de los dos bancos más grandes del país. En este contexto, la banca, con el beneplácito implícito del gobierno de Flores, ha comenzado a hablar de una operación destinada a salvar aquellas empresas amenazadas por la quiebra. Es así como el gobierno se apresta a crear un fondo destinado a refinanciar a dichas empresas. Pero, dada la dinámica del capital salvadoreño y la política pública, lo normal es que sólo sean sujeto de refinanciamiento las grandes empresas, vinculadas además al gran capital bancario.

Es normal entonces que los empresarios amenazados por la voracidad de los bancos y del capital multinacional se resistan a continuar apoyando a un partido político cuyo gobierno los abandona a su suerte cuando, de acuerdo a la práctica establecida, debiera ayudarlos a salir de la crisis. De esta manera, primero cayó el sector agropecuario, $y$ ahora le toca el turno a la empresa privada más débil. Los únicos ganadores aparentes de este nuevo ataque serían los bancos más grandes. Pero el sabor del triunfo puede durar poco 
tiempo, si ellos también llegan a caer, víctimas de su propia voracidad insaciable e ilimitada. La fuerza que han desatado es tan destructiva que también puede acabar con ellos.

Mientras tanto, Flores y su gobierno se han colocado del lado de los ganadores, siguiendo la política establecida por el primer gobierno de ARENA. Sus dificultades, pues, no se deben, ni mucho menos, a una mala comunicación. Objetivamente, el gobierno se encuentra atrapado entre las herencias del mal gobierno de su antecesor, la voracidad insaciable del gran capital nacional y multinacional, y los vaivenes del capitalismo internacional. La opinión pública ha captado esta situación de entrampamiento de una manera acertada al coincidir en que no es Flores quien gobierna El Salvador, sino una fuerza superior. Subjetivamente, Flores, pese a su discurso, no se ha mostrado dispuesto a sacar a su gobierno de la trampa en la que ha caído, ya sea porque se siente impotente o porque es cómplice. A veces pareciera que se debe más a lo segundo que a lo primero, dado su empeño sistemático por evadir y ocultar la realidad nacional. Cualquiera que sea la razón, el gobierno de Flores no se muestra dispuesto a revisar la dirección de la política económica, al menos por ahora. Más bien pareciera estar a la espera de que ocurra algo maravilloso que, de una manera inesperada, resuelva las contradicciones socioeconómicas de la sociedad salvadoreña.

... los beneficios del crecimiento no han llegado a los trabajadores, ya no digamos a quienes ni siquiera tienen empleo.

Contrario a lo propuesto por los gobiernos de ARENA, el crecimiento de la década de los noventa ha sido marginador y excluyente, en particular en el sector rural.

\section{La reforma estructural inexorable}

Las alternativas con las cuales Flores parece contar son, pues, dos. La primera sería una intervención maravillosa que por un golpe de fuerza elevara la tasa de crecimiento económico al nivel de comienzos de la década, aumentara el empleo y disminuyera el subempleo, aumentara los salarios y no disparara la inflación, hiciera crecer las exportaciones cerrando la brecha abierta por las importaciones y redujera el déficit fiscal de forma drástica. La absolutización del libre comercio produce "alucinaciones ideológicas" en gobiernos que, como el de El Salvador, creen ver delante de sí la solución de todos sus problemas internos en la intervención de factores externos como la inversión extranjera y, o los tratados de libre comercio con Norteamérica, las Américas o el Caribe. Sin duda, ambos factores son importantes para estimular el desarrollo económico y social de cualquier país del tercer mundo, pero nunca podrán reemplazar las transformaciones internas, las cuales son inevi- 
tables. Unas transformaciones que El Salvador ha ido posponiendo por décadas, en un vano intento por obtener unas ventajas económico sociales sin costo político alguno.

Por ahora, esta alternativa no es realista. En primer lugar, porque, de hecho, El Salvador es el país que menos inversión extranjera ha recibido en los últimos años. La explicación puede estar en unos riesgos que el inversionista considera demasiado elevados. Los puntajes altos que las calificadoras de riesgo otorgan a El Salvador han servido más para el consumo interno que para influenciar las decisiones del capital multinacional, que, sin duda, se toma muy en serio los riesgos jurídicos y de seguridad, así como también la calificación de la fuerza de trabajo. En segundo lugar, porque Estados Unidos y Canadá, los socios mayores de los tratados de libre comercio, son muy reacios a abrir sus fronteras y porque los socios menores, como los países centroamericanos y caribeños, con mucha dificultad se ponen de acuerdo sobre los productos que circularán libremente y las reglas de origen, lo cual les resta fuerza y credibilidad en la mesa de negociación. Estos países no creen que las restricciones - reales o a veces supuestas - que supone formar parte de un esquema de integración sean menores que los beneficios que podrían obtener al negociar como bloque. $\mathrm{Y}$ aun cuando se llegaran a abrir nuevos mercados, es dudoso que la industria salvadoreña tenga capacidad para aprovechar esta oportunidad.

En la práctica, esto deja a El Salvador a merced de los vaivenes del capitalismo internacional, los cuales son impredecibles. Ciertamente, una combinación favorable de factores externos siempre puede tener un impacto positivo en la economía nacional. Pero mientras esa combinación se da, no pareciera haber otra alternativa que aceptar el orden establecido por los bancos y el capital multinacional en El Salvador, tal como el presidente Flores propone como segunda alternativa. Mientras se aguarda la llegada de esa intervención externa capaz de resolver las contracciones actuales, habría que resignarse a convivir bajo ese régimen, sometiéndose a sus dictados. Es lo que el gobierno de Flores quisiera conseguir con buenos modales y palabras, aunque, si fuera necesario, no hay que poner en duda su disponibilidad para acudir a la fuerza.

Ninguna de las alternativas que el gobierno contempla ofrece una solución verdadera. El resultado de las dos es, al final de cuentas, muy similar. Si por un acaso llegaran a coincidir una inversión extranjera vigorosa con algún tratado de libre comercio ventajoso para El Salvador, los indicadores económicos y sociales mejorarían sin duda alguna, pero sólo temporalmente, tanto cuando convenga a los intereses de los inversionistas y de los socios mayores, cuyas decisiones obedecen a criterios de rentabilidad y no de humanidad, desarrollo sostenible o solidaridad. Es decir, el país seguiría sometido a los caprichos del mercado y del capital transnacional. En definitiva, El Salvador seguirá siendo tan vulnerable como lo es ahora. 
Habría, sin embargo, una tercera alternativa que consiste en superar las limitaciones estructurales que en la actualidad se presentan como insuperables, pero que unas reformas audaces y bien pensadas podrían echar abajo, en el mediano y el largo plazo. Además, la experiencia demuestra con claridad meridiana que dichas reformas no pueden posponerse más. Sin ellas, la inversión extranjera y los tratados de libre comercio no tendrán mayor impacto en la economía nacional. El gobierno de Flores podría comenzar combatiendo la corrupción rampante, acrecentando la eficacia de la gestión pública, implantando una austeridad rigurosa y sin excepciones y vigilando estrechamente la ejecución del presupuesto nacional. El ahorro que estas acciones dejaran podría destinarse a ampliar el gasto social a los sectores más empobrecidos de la población, a la inversión pública y a promover la actividad económica para crear empleo.

Capítulo aparte es la reactivación del sector agropecuario. Poco puede hacer el gobierno salvadoreño para elevar los precios de las exportaciones tradicionales, cuyos precios son fijados por el mercado internacional. Cada vez podrá hacer menos respecto a la producción y comercialización de los granos básicos y la ganadería, dada la apertura promovida por los gobiernos de ARENA. Sin embargo, todavía puede hacer mucho, si adopta una estrategia para promover la exportación de productos no tradicionales. El interés que los agregados comerciales salvadoreños destacados en las representaciones diplomáticas puedan tener en la identificación y apertura de mercados, es sólo parte de lo que debiera ser un plan de mucho mayor envergadura, que comprenda crédito y asistencia técnica para los productores pequeños y medianos. Para tener éxito en esta empresa, habría que hacer un esfuerzo similar al llevado a cabo a finales del siglo XIX para insertar a El Salvador en el mercado capitalista mundial con el café.

Simultáneamente, habría que trabajar duro y rápido en la creación de la institucionalidad del país. La década de postguerra ha demostrado la fragilidad y la obsolescencia de una institucionalidad anterior a la guerra y, por lo tanto, complicada, contradictoria y desactualizada, tanto teórica como prácticamente. Los acuerdos de paz y el proceso de transición iniciado apenas la han tocado; sin embargo, sí han puesto al descubierto la necesidad urgente de replantearla desde sus fundamentos. Sólo una institucionalidad fuerte y eficiente podrá ejecutar las medidas propuestas arriba.

En un segundo momento, cuando la economía haya recuperado un ritmo de crecimiento más dinámico, el gobierno podría profundizar el proceso y emprender la reforma tributaria tanto tiempo postergada. El Salvador sigue siendo uno de los pocos países latinoamericanos con menor carga tributaria. Los más ricos rechazan pagar impuestos en proporción a sus ganancias y posesiones porque lo consideran confiscatorio. Pero las necesidades del país y la moral más elemental han vuelto esta medida impostergable. El primer 
sector castigado con la reforma tributaria regresiva, ejecutada por los dos primeros gobiernos de ARENA, ha sido el menos favorecido, por lo tanto, es política y moralmente justo obligar ahora a los sectores que perciben los ingresos más elevados del país a contribuir con su parte. Ya es hora de forzarlos a participar activamente en la redistribución de la riqueza nacional $y$ en la solidaridad.

Esta reformas y otras que debieran seguir sólo serían posibles mediante una participación ciudadana vigorosa y creativa, que además contribuiría de una manera importante a democratizar El Salvador y podría incluso llegar a convertirse en un apoyo sólido para las alianzas que Flores querría establecer. La participación ciudadana, sin embargo, no es exclusiva de este gobierno, sino que es una necesidad de cualquiera que se decida a transformar las estructuras sociales de El Salvador. El presidente Flores, por el momento, tiene a su favor la valoración positiva que la opinión pública hace de su persona, lo cual, aparentemente, contradice el predominio de los juicios negativos sobre su desempeño en los primeros cien días de gobierno. Pero no hay tal contradicción, sino un deseo muy sentido de no perder toda esperanza. La opinión pública se resiste a creer que tenga que resignarse a aceptar un orden que la despoja de lo poco que tiene y que la excluye de las pocas oportunidades que se le puedan presentar. Por eso se aferra a la persona del Presidente de la República como última posibilidad.

Es el mito del jefe bueno y de los subalternos malos. Estos actúan mal porque aquél desconoce sus malas acciones, pero si las conociera, seguramente, los castigaría y restablecería el orden. Esta percepción concuerda con aquella otra que sostiene que Flores no es quien gobierna, sino una fuerza superior a él; si él asumiera las riendas del gobierno, las cosas serían muy diferentes. Si Flores se apoyara en la aceptación de la cual goza su persona entre la población, podría encontrar un estímulo y un apoyo importantes para comenzar las reformas estructurales necesarias y urgentes. Por otro lado, ésta sería la mejor manera de corresponder a la confianza depositada en él por la población que lo percibe como su última posibilidad.

En sus primeros cien días de su gobierno, el presidente Flores ha estado luchando inútilmente contra la realidad nacional con muy poco éxito. Una realidad nacional que no desconocía, pero que tal vez pensó que podría gobernar, que sus ideas de armonía universal podrían contribuir a apaciguar y canalizar de la forma más adecuada, pero cuyo poder ha resultado superior a lo esperado. Sus ideas preconcebidas y sus prejuicios se han quedado cortos y los primeros cien días de gobierno se han perdido en la inanidad y la irrelevancia. La realidad salvadoreña supera su capacidad y sus planes, cualesquiera que éstos sean. Cada vez resulta más difícil conservar intacto el orden establecido por los grandes bancos y el gran capital multinacional. 
Las reformas estructurales se han pospuesto por demasiado tiempo. Cada posposición se vio como un triunfo y se pensó que se ganaba tiempo; pero, en realidad, fue una ilusión porque, en lugar de contribuir a resolver los problemas, los agravó e hizo más difícil su posible solución. Lo único que se consiguió fue cerrar posibilidades y endurecer las posturas de quienes calculaban que se podía avanzar un poco más sin hacer cambios. La última posposición fue la de los acuerdos de paz. Desde entonces, la transición transcurre a contra pelo de las reformas socioeconómicas. En la actualidad, el tiempo apremia porque las condiciones en las cuales se encuentra El Salvador son tales que lo poco que se haya podido ganar, a costa del sacrificio del pueblo salvadoreño, podría estar a punto de echarse a perder.

San Salvador, 5 de octubre de 1999. 